REVIEW ARTICLE

\title{
Genetic Polymorphism of NAT2 Gene and its Association with Prostate Cancer
}

\author{
A Nesa ${ }^{1}$, MT Rahman ${ }^{2}$, Y Kabir ${ }^{3}$, FA Rupam ${ }^{4}$ \\ ${ }^{1}$ Asstt Professor, Pathology, Ibrahim Medical College \\ ${ }^{2}$ Professor \& Head Pathology, Anwer Khan Modern Medical College \\ ${ }^{3}$ Professor of Biochimistry, University of Dhaka \\ ${ }^{4}$ Public Health Specialist
}

*Corresponding Author

ABSTRACT

A N acetyltransferases 2 (NAT2) is one of the phase II metabolizing enzyme that participate in the bioconversion of heterocyclic arylamines into electrophilic nitrenium ions, which are important ultimate carcinogens that are directly implicated in tumor initiation process. Prostate epithelial cell express $\mathrm{N}$ acetyltransferases (NAT) enzymes and recent molecular epidemiological studies have analyzed the relationship between NAT2 in etiology of prostate cancer. A review by chen (2001) in prostate cancer $(\mathrm{PCa})$ suggests that the frequencies of some polymorphisms in certain genes differ among different racial and ethnic groups. In a case control study in India by Srivastava and Mittal (2005), observed significant association between rapid acetylator genotype NAT2 and PCa in tobacco users $(\mathrm{OR}=3.43,95 \% \mathrm{CI}: 1.68-7.02, \mathrm{p}<0.001)$ when compared with controls. Hamasaki et al (2003) in Japanese men, observed the frequency of the NAT slow acetylator genotype was statistically higher among prostate cancer patients (17.1\%) compared with controls (8.6\%). Another case control study in Turkey by Kosova et al. (2009), concluded that Nat2*6A and NAT2 *7A/B gene polymorphism were significantly associated with prostate cancer.

Key Words: NAT2 gene, Prostate cancer.

\section{Introduction}

Prostate cancer is the most common cancer affecting men and is a major medical problem. African- American men have the highest rate of prostate cancer in the world (incidence approximately 149 per 100000 person/year). ${ }^{1}$ The etiology of prostate cancer is not well understood, however studies examining genetics, diet and lifestyle are increasingly attracting attention. Cigarette smoking, high fat diet and the consumption of overcooked red meat, increase exposure of aromatic amines and heterocyclic amine, 2,3 both of which are genotoxic chemicals, acquire bioactivation and inactivation by enzymes. ${ }^{4}$ If these carcinogens are metabolically active they can initiate carcinogenesis by damaging DNA. ${ }^{5}$ Through $\mathrm{N}$ oxidation or $\mathrm{O}$ acetylation by -Acetyltransferase (NAT) enzymes N-hydroxy aromatic and heterocyclic amines are activated to acetoxy intermediary compounds, which can bind to AKMMC J 2014; 5(2): 39-42
DNA and produce adducts. ${ }^{6}$ It was reported prostate epithelial cell express phage II metabolizing NAT enzymes and recent molecular epidemiological studies have analyzed the relationship between $\mathrm{N}$ acetyltransferases in etiology of prostate cancer. ${ }^{7,8,9,10}$

\section{Literature Review and Discussion}

NAT are encoded by two genes, NAT1 and NAT2 located in chromosome 8p 21.3-23.1.11 Both genes are highly polymorphic. NAT2 is one of the phase II metabolizing enzyme that participate in the bioconversion of heterocyclic arylamines into electrophilic nitrenium ions, which are important ultimate carcinogens that are directly implicated in tumor initiation process. ${ }^{12}$ NAT2 gene is quite polymorphic and there are 29 NAT2 alleles have been identified. Some of these polymorphisms can affect enzyme activity; e.g., 2 or more polymorphisms 
result in a slow acetylator phenotype, whereas a heterozygote or wild type genotype results in a rapid or medial acetylator phenotype. Consequently, the acetylation ratio of drugs and carcinogens can change with respect to an individual's acetylator phenotype and predispose them to diseases like cancer. ${ }^{13}$

A review by chen (2001) in prostate cancer suggests that the frequencies of some polymorphisms in certain genes differ among different racial and ethnic groups. ${ }^{14}$ The populations of Europe and North America contain from $40-70 \%$ of slow acetylators, whereas only $10-30 \%$ of slow acetylators were found among the populations of Asian Pacific coast (Japanese, Chinese, Koreans). ${ }^{15}$ In Caucasian populations, the NAT2 M1 allele is the most frequent allele $(40-50 \%)$, in contrast to Asian populations, which exhibit a very low frequency $(0-5 \%) .16,17,18,19$

The first identi?ed and most commonly detected NAT2 alleles in Caucasian populations are the wild type $\mathrm{NAT} 2 * 4$, as well as the "'slow"' NAT $2 * 5$ and NAT $2 * 6$ alleles. $(20,21,22)$ In contrast, the "'slow'" NAT2*5 allele is extremely rare in Oriental populations, difference compensated for by an increased frequency of the "'rapid"' NAT2*4 allele. $(23,24)$

A study were conducted by Lima Junior et al (2011) in Latin American patients, found there was an association between NAT2T481C $(\mathrm{OR}=0.47,95 \% \mathrm{CI}=0.26-0.84 ; \mathrm{P}=0.01)$ and NAT2A803G $\quad(\mathrm{OR}=0.57 ; 95 \% \quad \mathrm{CI}=0.33-$ $0.97 ; \mathrm{P}=0.04) \quad$ polymorphism and $\mathrm{PCa}$ protection, conversely the presence of NAT2G857A genotype increased the risk of $\mathrm{PCa}$ more than 3 times $(\mathrm{OR}=3.57 ; 95 \%$ $\mathrm{CI}=1.39-9.15 ; \mathrm{P}=0.005)$. They also found slow acetylator NAT2*7A and NAT2*6B genotypes occurred in $10.31 \%$ of $\mathrm{PCa}$ but in none of $\mathrm{BPH}$ patients $(\mathrm{P}=0.0007) .{ }^{25}$ However a study among men of African descent by Kidd LCR et al (2011) did not observe strong main or gene combination effects of NAT1 and NAT2 polymorphisms in relation to $\mathrm{PCa}$ risk. ${ }^{26}$
A meta-analysis of the NAT1 and NAT2 polymorphisms and prostate cancer by Gong $\mathrm{C}$ et al (2010) revealed, a statistically significant association between NAT2 polymorphism and prostate cancer appeared in Asians, but not in Caucasians. But they concluded that, the NAT1 and NAT2 phenotypes detoxify carcinogen and their intermediates are unlikely to be cause of PCa development. ${ }^{26}$

A case control study in Turkey by Kosova et al. (2009) with 150 unrelated healthy men and 110 unrelated patients with prostate cancer show prostate cancer patients had a higher frequency of mutant NAT2 *6A and heterozygous NAT2*7A/B genotypes when compared with the control. They concluded that Nat $2 * 6 \mathrm{~A}$ and NAT2 *7A/B gene polymorphism were significantly associated with prostate cancer in Turkish population. ${ }^{13}$

Another study of NAT2 and nucleotide excision repair (NER) genetic variant and prostate cancer susceptibility in African American by Hooker et al. (2007) showed possible relationship between polymorphism in NAT2 and NER gene and prostate cancer risk in African American is twice than that of European American. ${ }^{27}$

In another case control study in India by Srivastava and Mittal (2005) over a period of 28 months that included 130 patients and 140 controls, they observed a trend of association of NAT2 $\quad(\mathrm{OR}=1.452, \quad \mathrm{CI} 95 \%, \quad 0.5-1.87$, $\mathrm{p}=0.136)$ gene in prostate cancer risk but which was statistically nonsignificant. However significant association was observed between rapid acetylator genotype NAT2 and $\mathrm{PCa}$ in tobacco users $(\mathrm{OR}=3.43,95 \% \mathrm{CI}: 1.68-7.02$, $\mathrm{p}<0.001)$ when compared with controls. The data suggest that NAT2 genotype may play an important role in detecting the risk of developing prostate cancers particularly in tobacco users. ${ }^{12}$ The meta analysis conductedby Huncharek and colleagues (2010), pooled findings from numerous studies, revealed consistent evidence that both the chance of developing $\mathrm{PCa}$ and dying from $\mathrm{PCa}$ increases with smoking. ${ }^{28}$ 
Again Ratnasinghe et $\mathrm{al}^{10}$ reported that rapid NAT2 phenotype was a risk factor for prostate cancer. Fukutome et $\mathrm{al}^{9}$ observed that there was an increased NAT1*10 homozygote in PCa cases and Hein et $\mathrm{a}^{29}$ also found that this genotype was a risk for PCa. In contrast, Wadelius et $\mathrm{al}^{30}$ and Norrish et $\mathrm{al}^{31}$ reported no association between NAT2 and PCa.

Hamasaki et al $(2003)^{32}$ in Japanese men, observed the frequency of the NAT slow acetylator genotype was statistically higher among prostate cancer patients $(17.1 \%)$ compared with controls $(8.6 \%)$ and exhibited a 2.2 fold increased risk of prostate cancer $(\mathrm{OR}=2.21 ; 95 \% \mathrm{CI}, 1.04$ 4.69; P-0.0289). However smokers with the slow acetlator genotype exhibited a statistically increased risk of prostate cancer $(\mathrm{OR}=3.87 ; 95 \% \mathrm{CI}, 1.48-9.66 ; \mathrm{P}=0.0041)$. Similarly Costa et al (2005) studied in a Southern European population and observed a statistically significant association of slow acetylator genotype, NAT2 $* 6 / \mathrm{NAT}_{2} * 6$ with prostate cancer protection $(\mathrm{P}=0.017, \mathrm{OR}=0.31,95 \% \mathrm{CI} 0.11-0.84) .^{5}$

Although the acetylator status of NAT2 in prostate cancers was investigated in several studies, the results were conflicting as to whether the slow or rapid acetylator status did constitute a risk factor. These inconsistencies may be due to variation in NAT2 allele distribution between interethnic populations6, as well as to exposure to environmental factors. Another fact is that the NAT2 gene is quite polymorphic and not all polymorphisms were analyzed at the same time in these studies. Only the most frequently observed polymorphisms were studied.

\section{Conclusion}

Since there have been a number of published reports on the association of NAT2 acetylation phenotypes and prostate cancer risk but the results revealing conflicting and there was no such research work, done in Bangladesh. So a study of genetic polymorphism of NAT2 gene and its association with prostate cancer should be evaluated in Bangladeshi population, which will lead to early diagnosis and better management and prevention of prostatic cancer patients.

\section{References}

1. Taylor JD, Holmes TM, Swanson GM. Descriptive epidemiology of prostate cancer in metropolitan Detroit. Cancer 1994; 73: 1704-7.

2. Sinha $\mathrm{R}$ et al. Heterocyclic amine content of pork products cooked by different methods and to varying degrees of doneness. Food Chem Toxicol 1998; 36: 289-297.

3. Sinha R et al. Heterocyclic amine content in beef cooked by different methods to varying degrees of doneness and gravy made from meat drippings. Food Chem Toxicol 1998; 36: 279-287.

4. Hein DW. N-Acetyltransferase genetics and their role in predisposition to aromatic and heterocyclic amineinduced carcinogenesis. Toxicol Lett 2000; 112-113: 349-356.

5. King CM, Land SJ, Jones RF, et al. Role of acetyltransferases in the metabolism and carcinogenicity of aromatic amines. Mutat Res 1997; 376: 123- 128.

6. Hein DW, Doll MA, Fretland AJ, et al. Molecular genetics and epidemiology of the NAT1 and NAT2 acetylation polymorphisms. Cancer Epidemiol Biomark Prev 2000; 9: 29-42.

7. Wang CY et al. N-Acetyltransferase expression and DNA binding of $\mathrm{N}$-hydroxyheterocyclic amines in human prostate epithelium. Carcinogenesis 1999; 20: 1591-1595.

8. Agundez JA et al. Expression in human prostate of drugand carcinogen-metabolizing enzymes: association with prostate cancer risk. Br J Cancer 1998; 78: 1361-1367.

9. Fukutome $\mathrm{K}$ et al. $\mathrm{N}$-acetyltransferase 1 genetic polymorphism influences the risk of prostate cancer development. Cancer Lett 1999; 136: 83-87.

10. Ratnasinghe LD et al. Increased NAT2 activity is associated with prostate cancer risk. Proc Am Assoc Cancer Res 2003; 44: 824.

11. Costa S, Pinto D, Morais A et al. Acetylation Genotype and the Genetic Susceptibility to Prostate Cancer in a Southern European Population. The Prostate 2005; 64:246- 252.

12. Srivastava DSL, Mittal RM. Genetic polymorphism of the N-acetyltransferase 2 gene, and susceptibility to prostate cancer: a pilot study in north Indian population. BMC Urology 2005; 5:12. 
13. Kosova B, Bozon CV, Cal AC et al. Nacetyletransferase 2 gene polymorphisms and susceptibility to prostate cancer: a pilot study in he Turkish population. Turk J Med Sci 2010; 40 (4): 629-636.

14. Chen C. Risk of prostate cancer in relation to polymorphism of metabolic genes. Epidemiol Rev 2001; 23:30-35.

15. Nikishina MV, Makarova SI, Akishev AG et al. Restriction analysis of $\mathrm{N}$ - Acetyltransferase 2 Gene in Caucasian Population of West Siberia. Russian Journal of Genetics 2004; 40(11): 1288-1291.

16. Inatomi $\mathrm{H}$, Katoh $\mathrm{K}$, Kawamoto $\mathrm{T}$, et al. NAT 2 gene polymorphism as a possible biomarker for susceptibility to bladder cancer in Japanese. Int. J. Urol. 1999; 6: 446-54.

17. Delemenie C, Sica L, Grant DM, et al. Genotyping of polymorphic N- acetyltransferase (NAT2) gene locus in two native African populations. Pharmacogenetics 1996; 6: 177- 85.

18. Henry JL, Chun-Ya H, Bruce KL, et al. Ethnic distribution of slow acetylator mutations in the polymorphic $\mathrm{N}$-acetyltransferase (NAT2) gene. Phara- macogenetics 1994; 4: 125-34.

19. Matsumoto T. Clinical and pathological signi?cance of vitamin $\mathrm{D}$ receptor gene polymorphism for prostate cancer which is associated with a higher mortality in Japanese. Endocr. J. 2001; 48: 543-9.

20. Blum M, Demierre A, Grant DM, et al. Molecular mechanism of slow acetylation of drugs and carcinogens in humans. Proc Natl Acad Sci USA 1991;88:5237-41.

21. Vatsis KP, Martell KJ, Weber WW. Diverse point mutations in the human gene for polymorphic Nacetyltransferase. Proc Natl Acad Sci USA 1991;88:6333-7.

22. Abe M, Deguchi T, Suzuki T. The structure and characterisation of a fourth allele of polymorphic Nacetyltransferase gene found in the Japanese population. Biochem Biophys Res Commun 1993;191:811-6.

23. Deguchi T. Sequences and expression of alleles of polymorphic arylamine $\mathrm{N}$-acetyltransferase of human liver. J Biol Chem 1992;267:18140-7.
24. Deguchi T, Mashimo M, Suzuki T. Correlations between acetylator phenotypes and genotypes of polymorphic arylamine $\mathrm{N}$-acetyltransferase in human liver. J Biol Chem 1990;265: 12757-60.

25. Kidd LCR, VanCleave TT, Doll MA et al. No association between variant $\mathrm{N}$-acetyltransferase genes, cigarette smoking and Prostate Cancer susceptibility among men of African descent. Biomark Cancer 2011;3:1-13.

26. Gong C, Hu X, Gao Y et al. A meta-analysis of the NAT1 and NAT2 polymorphisms and prostate cancer: a huge review. Med Oncol 2011; 28:365376.

27. Hooker S, Bonilla C, Akereyeni F et al. NAT2 and NER genetic varients and sporadic cancer susceptibility in African Americans. Prostatic Cancer and Prostatic Disease 2008;11: 349-356.

28. Huncharek M, Haddock KS, Reid R, et al. Smoking as a risk factor for prostate cancer: a meta-analysis of 24 prospective cohort studies. Am J Public Health. Apr; 2010 100(4):693-701. [PubMed: 19608952]

29. Hein DW et al. Association of prostate cancer with rapid $\mathrm{N}$ - acetyltransferase 1 (NAT1*10) in combination with slow $\mathrm{N}$ - acetyltransferase 2 acetylator genotypes in a pilot case-control study. Environ Mol Mutagen 2002; 40: 161-167.

30. Wadelius $M$ et al. Polymorphisms in NAT2, CYP2D6, CYP2C19 and GSTP1 and their association with prostate cancer. Pharma- cogenetics 1999; 9: 333-340.

31. Norrish AE et al. Heterocyclic amine content of cooked meat and risk of prostate cancer. J Natl Cancer Inst 1999; 91: 2038-2044.

32. Hamasaki $\mathrm{T}$, Inatomi $\mathrm{H}$, Katoh $\mathrm{T}$ et al. $\mathrm{N}$ acetyltransferase- 2 gene polymorphism as a possible biomarker for prostate cancer in Japanese men. International Journal of Urology 2003; 10: 167-173. 